\title{
Anti-predator defence mechanisms in sawfly larvae of Arge (Hymenoptera, Argidae)
}

\author{
Charles-Albert Petre ${ }^{\mathrm{a}}$, Claire Detrain ${ }^{\mathrm{b}}$, Jean-Luc Boevé ${ }^{\mathrm{a}}$ \\ ${ }^{a}$ Department of Entomology, Royal Belgian Institute of Natural Sciences, IRSNB-KBIN, Rue Vautier 29, B-1000 Bruxelles, Belgium \\ ${ }^{\mathrm{b}}$ Service d'Ecologie Sociale, Université Libre de Bruxelles, CP 231, Campus de la Plaine, Boulevard du Triomphe, B-1050 Bruxelles, \\ Belgium
}

\begin{abstract}
Larvae of the sawfly Arge (Hymenoptera, Argidae) are exposed to predators such as ants. Their defence mechanisms, which have been almost unstudied, were investigated by behavioural observations coupled to a morphological approach and by testing the bioactivity of several body parts. Arge larvae raised their abdomen when contacted by Myrmica rubra workers. The ants rarely bit a larva and generally retreated immediately, sometimes without contacting it. Most of those few ants that bit a larva then showed an uncoordinated walk. Crude hemolymph from a common species, A. pagana, was a feeding deterrent towards ants. Hemolymph extracts remained active up to a concentration of $0.8 \mu \mathrm{g}$ DW extract per microlitre solution, and were more active than integument and gut extracts. We also observed ants paralysed by extracts, especially from the gut. It is likely that this toxicity is due to a polypeptide, lophyrotomin, which is known to occur in A. pullata. Six or seven non-eversible ventro-abdominal glands occurred in all species studied (A. fuscipes, A. nigripes, A. ochropus, A. pagana, A. pullata, A. ustulata). These glands contain volatiles. We consider both types of chemicals to be important in defence, and we propose that the paralysing effect is a common feature among Arge species.
\end{abstract}

Keywords : Arge sawfly larvae ; Deterrence and paralysing bioactivities ; Hemolymph ; Predatory ants ; Ventral glands

\section{Introduction}

The sawflies form a large group of phytophagous insects with many species being defoliators of woody, ornamental and agricultural plants (Pschorn-Walcher, 1982; Wagner and Raffa, 1993). Arge sawfly larvae live freely on leaves of their host plant, typically along the leaf edge (Lorenz and Kraus, 1957) where they are exposed to natural enemies. Major predators of sawfly larvae include arthropods, such as ants, and birds (Benson, 1950). Knowledge on the chemical ecology of defensive strategies in sawfly larvae mainly concerns the Diprionidae, Tenthredinidae and Pergidae (e.g., Eisner et al., 1974; Boevé and Pasteels, 1985; Wagner and Raffa, 1993; Boevé and Schaffner, 2003). In contrast, very little is known about the way Arge larvae defend against these predators, but the following traits may be involved.

First, some species have a conspicuous appearance and live gregariously, although others are cryptic and live either alone or in groups (Lorenz and Kraus, 1957). It is well known that conspicuous visual cues often identify unpalatable prey, and that insectivorous birds learn to avoid these aposematic species (e.g., Guilford, 1990; Marples et al., 1994). Full-grown larvae of A. pagana Panzer are brightly coloured and gregarious. Boevé and Müller (2005) tested Arge sp. (later identified as A. pagana) on starlings, Sturnus vulgaris, which avoided feeding on a majority of the larvae. Second, the body of Arge larvae is covered by a relatively dense pubescence made of bristles that may be of protective value. Third, non-eversible ventral glands described from a few species (Maxwell, 1955) could function in chemical defence, as do the eversible ventral glands of Nematinae (Tenthredinidae) larvae that emit repellent volatiles (Boevé and Pasteels, 1985). Fourth, a toxin was detected in total extracts from $A$. pullata Zaddach (Kannan et al., 1988). The toxin, lophyrotomin, is a peculiar peptide composed of eight amino acids including four in configuration D (Oelrichs et al., 1977). Lophyrotomin and its toxic effect were first discovered in larvae of Lophyrotoma interrupta (Pergidae). These larvae feed on grasses and grazing cattle were killed by ingesting them (Williams et al., 1982). Similarly, the toxin of A. pullata larvae caused the death of sheep (Kannan et al., 1988). When these sawfly species are in outbreak densities, the losses in cattle may have very serious economic impacts (e.g., Thamsborg et al., 1987). 
The aim of the present work is to provide comparative data about defensive traits such as body appearance, pubescence or occurrence of ventral glands in larvae from several Arge species. We also tested the effectiveness of other body organs in the chemical defence of A. pagana (a common sawfly species in Western Europe). We therefore set up a series of bioassays using workers of Myrmica rubra L., a common ant species belonging to the guild of potential Arge larvae predators.

Table 1 Appearance and feeding habits of full-grown larvae of Arge species studied

\begin{tabular}{lllll}
\hline Species & Appearance $^{\mathrm{a}}$ & Distibution $^{\mathrm{b}}$ & Field host plant & Investigations $^{\mathrm{c}}$ \\
\hline A. fuscipes & $\mathrm{C}$ & Often I & Quercus & $\mathrm{a}, \mathrm{b}$ \\
A. nigripes & $\mathrm{C}$ & $\mathrm{A}$ & Rosa & $\mathrm{a}, \mathrm{b}$ \\
A. ochropus & $\mathrm{B}$ & $\mathrm{A}$ & Rosa & $\mathrm{a}, \mathrm{b}$ \\
A. pagana & $\mathrm{B}$ & $\mathrm{G}$ & Rosa & $\mathrm{a}, \mathrm{b}, \mathrm{c}, \mathrm{d}, \mathrm{e}$ \\
A. pullata & $\mathrm{B}$ & $\mathrm{G}$ & Betula & $\mathrm{a}, \mathrm{b}, \mathrm{e}$ \\
A. ustulata & $\mathrm{C}$ & $\mathrm{A}$ & Crataegus, Salix & a, b \\
\hline
\end{tabular}

${ }^{a}$ Cryptic (C) or bright (B) colouration.

${ }^{b}$ Isolated (I), or aggregated (A) on a plant, or gregarious (G), i.e., distributed on one or a few leaves only.

'Investigations carried out in the present study on body pubescence (a) and ventral glands (b) as well as by bioassays with larvae alive (c), crude hemolymph (d) and extracts from several body parts (e).

\section{Material and methods}

\subsection{Insects and plants}

Larvae were collected on their host plant in the field (Table 1): A. fuscipes Fallén, A. ustulata Linné (from Belgium), A. nigripes Retzius, A. ochropus Gmelin, A. pagana (Belgium and Germany), and A. pullata (Austria). They were maintained on their host plant in the laboratory, in plastic boxes with a regularly moistened filter paper, until used in experiments. The larvae were identified with Lorenz and Kraus (1957), and the two similar species, A. pagana and A. ochropus, were distinguished according to Chevin (1972). Vouchers are presently kept at the Royal Belgian Institute of Natural Sciences (Boevé collection). The distribution of larvae was recorded. The larvae were either "aggregated", (i.e., several larvae were on a same plant, but rarely more than one larva per leaf) or truly gregarious (i.e., forming a group that was distributed on a single leaf, or on several adjacent leaves).

A mature ant colony of $M$. rubra was collected in the field and maintained in the laboratory for use in the bioassays. It contained an estimated number of 500-1000 individuals. It was regularly fed sugared water and living dipteran larvae (Calliphora sp.).

The number of larval instars was determined by keeping 25 single A. pagana larvae in Petri dishes at $24-34{ }^{\circ} \mathrm{C}$ and searching daily for the presence of an exuvia, which indicated a moult. For each instar (L1, L2, etc.) the width of the head capsule was measured and the overall body appearance described. The larvae were reared up to the imago for sex determination.

\subsection{Body pubescence and ventral glands}

Morphological studies were done on fixed and ethanol preserved specimens from six Arge species (Table 1).

Bristle morphology was observed and recorded with a Philips XL30 ESEM scanning electron microscope (SEM). Bristles on abdominal segments III and IV were also observed under a binocular for their abundance and precise location on the body.

The studies of non-eversible ventral glands complement those by Maxwell (1955). Larvae were dissected to determine the presence of glands and to describe their general morphology. The volume of each gland was estimated and divided by the cubed width of the head capsule, which leads to a glandular index. Fixed larvae were embedded in paraffin, and parasagital sections of $7 \mu \mathrm{m}$ were stained with ferric trioxy-hematein-phloxinlight green and then observed by light microscopy. The precise location of the glandular duct opening was determined by SEM, which also confirmed the presence of glands observed in the dissections. 


\subsection{Defensive effectiveness}

The defensive effectiveness of A. pagana at L3-5 (i.e., the cryptic instars L3, L4 and some L5; see Fig. 1) and L5-6 (brightly coloured instars) was compared to that of Calliphora sp. used as control. A single larva (10 replications) was placed in an open box $(10 \times 10 \mathrm{~cm})$ containing 20 ants at $t=0$. Predator-prey interactions were noted, and filmed between $t=2$ and $5 \mathrm{~min}$. From these films lasting $3 \mathrm{~min}$ each, the number of ants contacting the larvae with mandibles was counted every $20 \mathrm{~s}$, whereas the number of larvae clearly bitten was counted throughout the 3 min period. With the sawfly-ant interactions, behaviours were recorded throughout the 3 min filmed, by counting the number of ants: approaching a larva (beyond approximately $1 \mathrm{~cm}$ ), contacting it with antennae, and contacting it, moreover, with mandibles. On video, it was sometimes difficult to tell whether these mandibular contacts corresponded or not to a bite, and we have therefore not distinguished them. Subsequent to the three possible events (i.e., approach, contact with antennae, contact with mandibles), the ants either retreated, which could be accompanied by an escape/running behaviour, or they showed no particular reaction ("neutral reaction"), that is, they behaved similarly before as after their interaction with the larva. Then, frequencies of retreats, as compared to neutral reactions, were calculated. After the experiment, all Arge and Calliphora larvae were followed for their possible development until pupation.

Long-term defensive effectiveness was also estimated. A leaf with a single settled A. pagana L5-6 was placed in a cylindrical container (diameter: $3.5 \mathrm{~cm}$, height: $7 \mathrm{~cm}$, with a moistened plaster bottom) and 10 ants were added. Larva and ants were left together for $24 \mathrm{~h}$. The survival and health state of the larva was recorded after these $24 \mathrm{~h}$ and after 3 days. The trial was replicated 12 times, always with new larvae and ants.

\subsection{Feeding deterrence of crude hemolymph}

A bioassay was set up to measure the deterrent effect of crude, larval hemolymph on ants. The integument of $A$. pagana larvae was pierced to collect hemolymph with a glass micropipette. Twenty ants placed in a Petri dish (diameter: $9 \mathrm{~cm}$ ) were simultaneously $(t=0)$ presented with two drops spaced $3.5 \mathrm{~cm}$ apart; one drop contained $4 \mu \mathrm{l}$ of hemolymph from a single larva and the other $4 \mu \mathrm{l}$ of charcoal-filtered tap water. The ants were previously starved for $15 \mathrm{~h}$, and then deprived of food and water for an additional $3 \mathrm{~h}$. At $t=3 \mathrm{~min}$, the number of ants feeding on each droplet was counted. This trial was replicated with 12 larvae, always using different ants. Moreover, the crude hemolymph from these larvae was pooled, then diluted and tested as well (12 replications per dilution). A deterrence rate (RD) was calculated (from Boevé and Schaffner, 2003) with the formula: RD (\%) $=(C-T) /(C+T)$, where $\mathrm{C}$ and $T$ are the total number of ants feeding on the control and test droplets, respectively.

\subsection{Feeding deterrence and paralysing effect of extracts from isolated body parts}

A similar bioassay was performed with several larval body parts of A. pagana and A. pullata. The latter species was used because it is known to be toxic (see Section 1). Hemolymph was collected as described above, and the other body parts such as the gut and integument were obtained by dissecting freeze-killed larvae. The body parts were extracted in pure ethanol, crushed when necessary, and then filtered on celite powder. The filtrate was evaporated under a nitrogen flow. The dried material was dissolved in a sucrose solution at $0.1 \mathrm{M}$ to obtain $8 \mathrm{mg}$ DW extract/ml sucrose solution (test solution). From A. pagana and A. pullata, 34 and 6 larvae yielded 270 and $215 \mu \mathrm{l}$ of crude hemolymph and 16.6 and $2.7 \mathrm{mg}$ DW of hemolymph extract, respectively. In the bioassay (see above) $50 \mu \mathrm{l}$ of this test solution was compared to $50 \mu \mathrm{l}$ of the sucrose solution (without extract; control solution) on 40 ants per Petri dish, by counting $C$ and $T$ at $t=5 \mathrm{~min}$. Ten-fold dilutions were also tested. Generally 12 replications were done per body part and concentration, less when the amount of material was too limited.

During these bioassays, we unexpectedly observed that extracts from both A. pagana and A. pullata paralysed the ants. On six of the replicates using extracts of $A$. pagana, we then counted the number of paralysed ants at $t=$ $7.5 \mathrm{~min}$. The ants were partly within or close to the test droplet.

\section{Results}

\subsection{Body appearance of Arge spp.}

The appearance of the studied Arge species is given in Table 1. The species A. ustulata, A. nigripes and A. fuscipes had a cryptic appearance while A. pagana, A. pullata and A. ochropus were brightly coloured during their last larval instar. Moreover, we made a follow-up of all larval instars in the common sawfly A. pagana of 
which the anti-predator defensive effectiveness was specifically investigated in this paper (see bioassay results).

Fig. 1. A. pagana larvae at different instars (L3-L6) on rose leaflets. Note that the body appearance at L5 can differ between male $(M)$ and female $(F)$ and that L6 individuals are always females. For more explanation, see text.
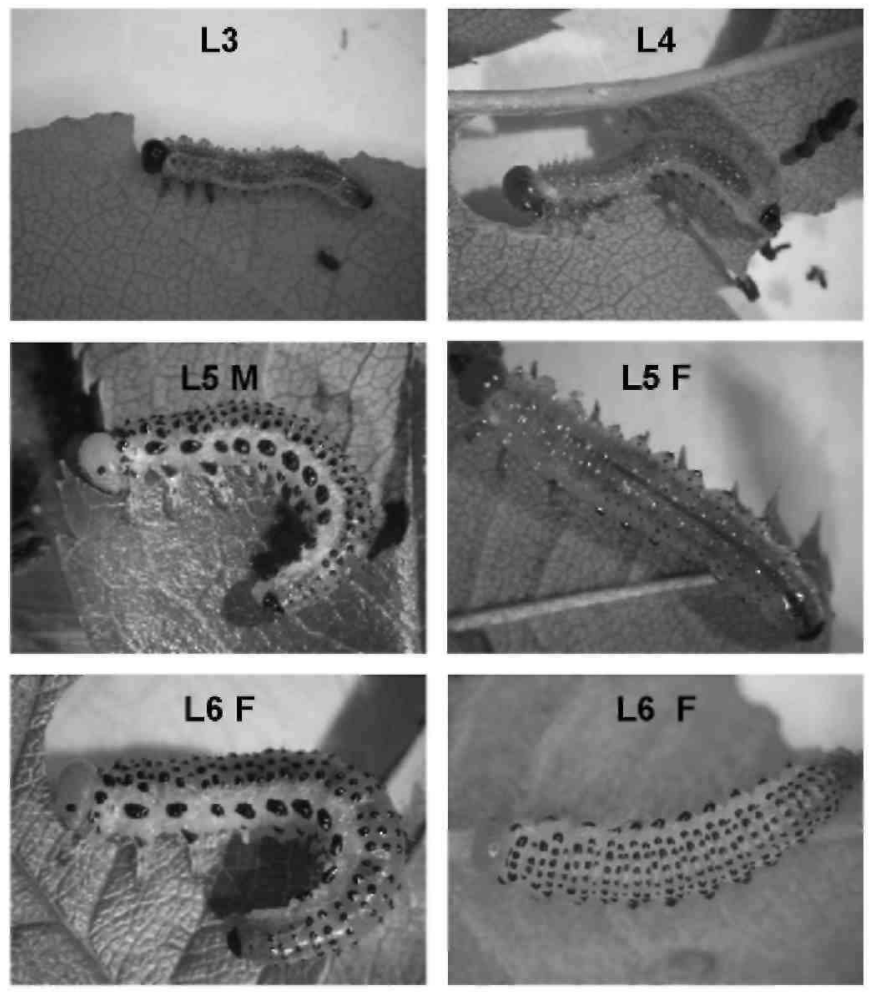

$5 \mathrm{~mm}$

A. pagana had five or six larval instars. Males (33\% of the individuals) always had five instars, but females were atypical for sawflies by not systematically having one instar more than males, but in having five (33\%) or six $(33 \%)$ instars. The mean width \pm S. D. $(N=25)$ of the larval head capsule was, in millimetre, $0.52 \pm 0.03$ (for L1), $0.84 \pm 0.04$ (L2), $1.11 \pm 0.03$ (L3), $1.44 \pm 0.06$ (L4), $1.65 \pm 0.09$ (L5) and $1.86 \pm 0.09$ (L6). Each instar lasted 2-4 days, leading to an overall larval period of approximately 13-17 days.

A. pagana displayed an alternating appearance during larval ontogeny (Fig. 1). During the two first instars, the larva displayed dorsal black spots. This pattern disappeared gradually in succeeding instars, but reappeared in the last instar. The background colouration of the integument varied as well during larval ontogeny, going from pale green at LI to bright yellow-green at the last instar. Moreover, during this last instar, the larva stopped feeding and became completely yellow 1 or 2 days before spinning a cocoon. The head colour changed also during instars, going from black to bright yellow. Thus, the overall visual effect is as follows: L3-4 is rather cryptic, L6 is brightly coloured, but L5 is either cryptic (for those females which will have a supplementary instar) or brightly coloured (for all males and for those females which end their larval development as L5).

\subsection{Gregariousness}

The distribution of larvae on their host plant is mentioned in Lorenz and Kraus (1957) and was complemented by our own field observations (see Table 1). A. fuscipes is considered as often solitary (Lorenz and Kraus, 1957) and no information about the distribution of larvae was available from our single sample of it. Three samples of A. nigripes were collected on different plants and at different dates, and they consisted of three L1 with eggs still visible on one leaflet, and two and six L4 which were aggregated. Generally, A. ochropus larvae were found aggregated. A. pagana was always gregarious: approximately 20 groups were collected with 5-27 larvae per 
group. A. pullata is also a typical gregarious species, which can defoliate young birch trees. The distribution of A. ustulata larvae was not known from the literature; three samples of them were collected: 24 L1 as well as four and eight aggregated larvae at further instars.

\subsection{Body pubescence}

The bristles were identified as mechanoreceptors (Fig. 2). They were of two sizes with lengths ranging either from 0.1 to $0.4 \mathrm{~mm}$, or from 0.04 to $0.08 \mathrm{~mm}$. Their density varied from one species to another when both bristle sizes were pooled. In increasing order: 59 bristles were counted per abdominal segment in A. pullata, 66 in A. ustulata, 132 in A. fuscipes, 154 in A. nigripes, 162 in A. pagana and 226 in A. ochropus.

\subsection{Ventral glands}

All species studied possessed non-eversible ventral glands on the abdomen (Table 2). The glands were situated, one per segment, along a median row. The secretory cells were in a spherical or ellipsoid grape-like cluster with a maximum diameter ranging from 0.32 to $0.62 \mathrm{~mm}$, depending on the species. The cluster was connected to a duct that opened on the second annulet of a segment (Fig. 3). The glandular duct was thin; its external diameter reaching approximately $20 \mu \mathrm{m}$ in A. pagana. The secretory cells were either broadly rounded or elongated and expanding in size towards the glandular lumina's side. Gland secretions were observed in the lumen. Depending on the species, glands were present on abdominal segments II-VII or II-VIII, and their volume varied from 7 to $49 \times 10^{-3} \mathrm{~mm}^{3}$ (Table 2).

Fig. 2. Pubescence of A. pagana. (A) Bristles on the dorso-abdominal part of a larva, by SEM; their mode of insertion and the absence of an aperture on their surface denote their function as mechanoreceptors. (B) Lateroabdominal pubescence, viewed from above a larva. (C) Larva curling its body, after it was suddenly disturbed.
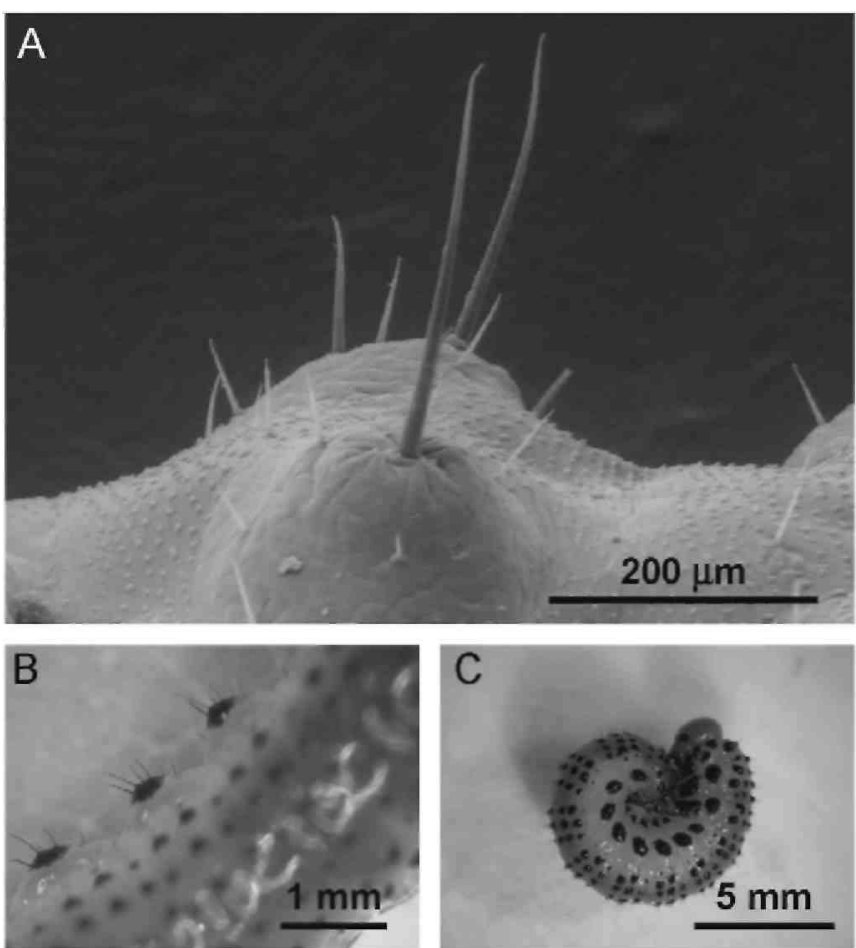

\subsection{Defensive effectiveness}

Ants surrounded all A. pagana and Calliphora larvae. However, fewer ants contacted the sawfly than the fly larvae. The mean number of ants contacting with mandibles an A. pagana larva was 0.6 at L3-5 and 0.1 at L5-6, but 7.5 for Calliphora sp. $(H=23.27, P<0.001$, d.f. $=2$, Kruskal-Wallis one-way analysis of variance; $P<$ 0.001 , Dunn post hoc test). The number of A. pagana L3-5, L5-6 and Calliphora larvae unambiguously bitten 
was 6, 1 and 10, respectively. All Calliphora larvae were violently attacked and subsequently killed, whereas all A. pagana larvae survived.

The A. pagana larvae raised their abdomen when ants contacted them for several seconds, especially when head or thorax of the larva was contacted. They directed their abdomen towards the aggressor(s). When ants just approached a larva, 1 and 16 retreats were counted with L3-5 and L5-6, respectively. After antennal as well as mandibular contacts, relatively more retreats of the ants were counted with L5-6 than with L3-5 (Fig. 4). Thus, especially the L5-6 proved to be defended, even at distance. These larvae, compared to L3-5, induced more ants to retreat subsequent to an antennal contact $\left(\chi^{2}=26.74, P<0.001\right.$, d.f. $=1$, Chi-square test for two independent samples; L3-5 vs. L5-6) as well as a mandibular contact $\left(\chi^{2}=6.34, P<0.02\right)$.

Table 2 Characteristics of ventro-abdominal glands in Arge larvae

\begin{tabular}{|c|c|c|c|}
\hline Species $(\mathrm{HCW})$ & $\begin{array}{l}\text { Gland on } \\
\text { abdominal segment }\end{array}$ & $\begin{array}{l}\text { Gland volume } \\
\left(10^{-3} \mathrm{~mm}^{3}\right)\end{array}$ & $\begin{array}{l}\text { Glandular Index } \\
\left(10^{-3}\right)\end{array}$ \\
\hline A. fuscipes (1.6) & II-VIII & $7 \pm 1$ & 1.7 \\
\hline A. nigripes (1.6) & II-VII & $27 \pm 7$ & 6.6 \\
\hline A. ochropus (1.9) & II-VIII & $21 \pm 4$ & 3.1 \\
\hline A. pagana (1.8) & II-VIII & $27 \pm 8$ & 4.6 \\
\hline A. pullata (2.4) & II-VIII & $49 \pm 29$ & 3.5 \\
\hline A. ustulata (1.5) & II-VIII & $7 \pm 1$ & 2.1 \\
\hline
\end{tabular}

Species name with the head capsule width (HCW, in millimetre). Gland volume by mean + S.D.

Fig. 3. Non-eversible ventral glands in A. pagana. (A) SEM view of the opening (arrow) of glandular duct, here between visible pseudopodes. (B) Lateral view of a dissected gland, showing, from left to right, the assemblage of secretory cells, the glandular duct, the integument and several bristles. (C) Transversal section, by light microscopy, through the assemblage of secretory cells, which are of two types. Secretion occurs in the lumina, GL. (D) Longitudinal section, by light microscopy, through the glandular duct, GD, linking the gland, GL, itself to exterior, OUT.
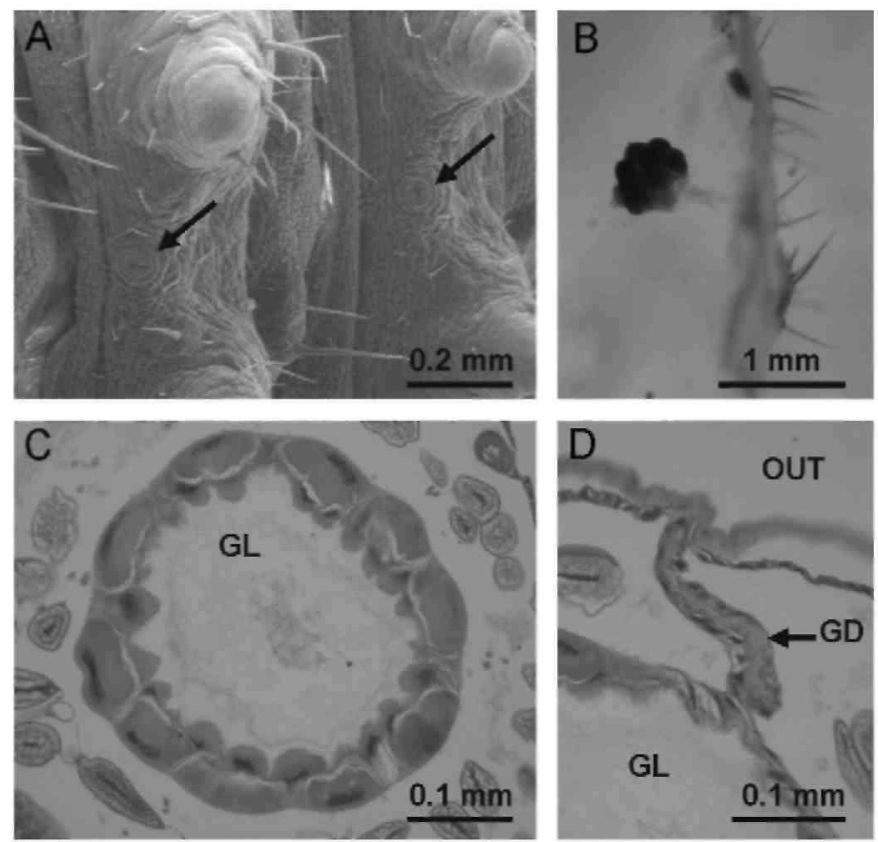

After biting A. pagana L3-5, four of six ants showed an uncoordinated walk, and this symptom lasted 5-47 s (within the timeframe of the experiment). Such a walk was not observed with L5-6. The interactions between ants and Calliphora larvae were more difficult to analyse, due to the high numbers of attacking ants (see above). However, 37 ants were identified as having bitten a larva and none showed an uncoordinated walk. Thus, this symptom is closely associated with the fact that the ants previously bit an A. pagana larva $(P<0.001$, Fisher's 
exact probability test).

In the bioassay on the long-term defensive effectiveness, all 12-tested larvae of A. pagana were still alive after a $24 \mathrm{~h}$ confrontation with ants. Nevertheless, seven larvae were wounded and died within 3 days; the other five completed their development normally.

\subsection{Feeding deterrence of crude hemolymph}

The crude hemolymph of A. pagana showed strong feeding deterrence activity. The deterrence rate was $95 \%$ with the undiluted hemolymph (total number of ants feeding on the test and control droplets: 75), 94\% with a $1: 10$ dilution (68), 33\% with a 1:100 dilution (95) and 9\% with a 1:333 dilution (104). These rates were significant $(T=0$ three times, $P<0.01$, Wilcoxon matched-pairs signed-ranks test), except the latter one $(T=$ 14.5, $P>0.05)$. Many ants that started to feed on the undiluted crude hemolymph then walked backwards while keeping their antennae and mouthparts on the substrate. Subsequently, they cleaned their antennae but continued their uncoordinated walk, sometimes for several minutes. This behaviour was observed with the 10-fold dilution of the hemolymph, but not with subsequent dilutions.

\subsection{Feeding deterrence and paralysing effect of extracts from isolated body parts}

Ethanolic extracts from hemolymph, integument and gut of A. pagana and A. pullata deterred ants at the start concentration of $8 \mathrm{mg}$ DW extract/millilitre solution. In both sawfly species, the hemolymph extract showed the strongest activity, followed by the gut and then the integument extract (Table 3). The hemolymph remained active at $0.8 \mathrm{mg} / \mathrm{ml}$, and no body part was still active at $0.08 \mathrm{mg} / \mathrm{ml}$. The extract from salivary glands plus fat bodies of $A$. pullata was never deterrent.

When testing the extracts of body parts, we were surprised to observe that a majority of ants starting to feed on the test droplet were rapidly paralysed. Immobilisation could occur within only a few seconds. This symptom was never observed with a control droplet. With A. pagana larvae, it was strongest when the ants fed on the gut extract (Table 4).

Table 3 Deterrence rate (\%) and paralysing effect of ethanolic extracts from several body parts of Arge larvae

\begin{tabular}{llll}
\hline Body part & \multicolumn{3}{l}{ Concentration $(\mathrm{mg} / \mathrm{ml})$} \\
\cline { 2 - 4 } & 8 & 0.8 & 0.08 \\
\hline A. pagana & $23^{* *}(196) \mathrm{PE}$ & $-2^{\mathrm{ns}}(159)$ & \\
Integument & $83^{* *}(140) \mathrm{PE}$ & $13^{* *}(217) \mathrm{PE}$ & $1^{\mathrm{ns}}(249)$ \\
Hemolymph & $34^{* *}(168) \mathrm{PE}$ & $11^{\mathrm{ns}}(165) \mathrm{PE}$ & \\
Gut (including its contents) & & & \\
A. pullata & $47^{* *}(132) \mathrm{PE}$ & $9^{*}(167)$ & $-11^{\mathrm{ns}}(122)$ \\
Integument & $98^{*}(89)^{\dagger \dagger}$ & $17^{* *}(197)$ & $3^{\mathrm{ns}}(199)$ \\
Hemolymph & $80^{*}(51)^{\dagger} \mathrm{PE}$ & $10^{\mathrm{ns}}(207)$ & \\
Gut wall & $68^{*}(63)^{\dagger} \mathrm{PE}$ & $40^{* *}(63)^{\dagger \dagger} \mathrm{PE}$ & $1^{\mathrm{ns}}(182)$ \\
Gut content & $-5^{\mathrm{ns}}(126)^{\dagger \dagger} \mathrm{PE}$ & & \\
Fat bodies and salivary glands & &
\end{tabular}

Values between parentheses are the total number of ants feeding on the test and control droplets. PE: Paralysing effect observed at least in several ants that previously fed or were feeding on the test droplet. ${ }^{*} P<0.05 ; * * P<0.01$; ${ }^{\text {ns }}$ not significant with $P>0.05$, Wilcoxon matched-pairs signed-ranks test.

${ }^{\dagger} 6$ replications performed (instead of 12).

17 replications performed (instead of 12).

部 8 replications performed (instead of 12).

Table 4 Percentage of paralysed ants around or in test droplet from A. pagana extracts

\begin{tabular}{lllllll}
\hline $\begin{array}{l}\text { Concentration } \\
(\mathrm{mg} / \mathrm{ml})\end{array}$ & \multicolumn{2}{l}{ Integument } & \multicolumn{2}{l}{ Hemolymph } & Gut & \\
\cline { 2 - 7 } & $\mathrm{PE}$ & $\mathrm{TD}$ & $\mathrm{PE}$ & $\mathrm{TD}$ & $\mathrm{PE}$ & $\mathrm{TD}$ \\
\hline 8 & 8 & 18 & 1 & 3 & 10 & 8 \\
0.8 & 0 & 19 & 2 & 19 & 10 & 14
\end{tabular}

Percentages of ants showing a paralysing effect (PE) and of those that fed on the test droplet (TD), as compared to the total number of ants involved in the bioassay. 
Fig. 4. Frequency of retreats by Myrmica rubra ants after contacting with antennae or mandibles an Arge pagana L3-5 or L5-6. Total number of retreats and "neutral" reactions are given above each bar.

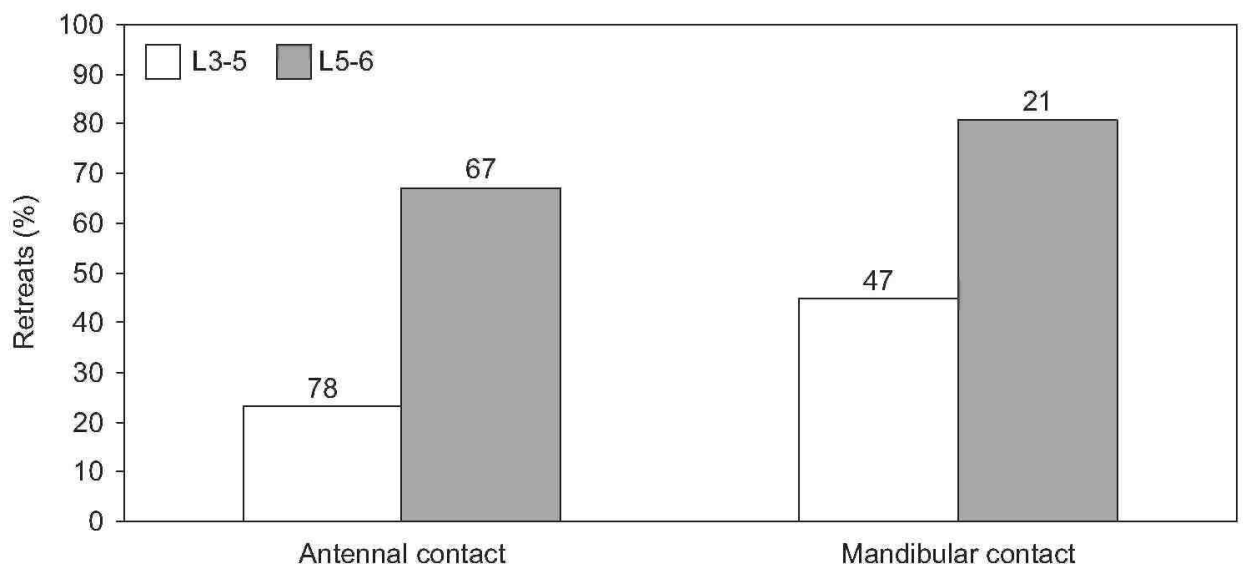

\section{Discussion}

Bright colouration and gregariousness are generally linked traits in insects (Fisher, 1930; Guilford, 1990; Ruxton and Sherratt, 2006), which is observed as a trend in Arge species. Two of the three brightly coloured species were truly gregarious, whereas the cryptic species were generally aggregated or encountered in groups composed of a few individuals only. In A. pagana, appearance at L5 is sex biased (Fig. 1) which may, in theory, cause a correspondingly biased predation pressure by naïve birds on a group of larvae coming from one egg batch. Male larvae would suffer from a higher predation than female larvae.

Pubescence linked to a defensive behaviour is known to act against attacks by predators such as birds. Starlings avoid preying on A. pagana larvae (Boevé and Müller, 2005). Full-grown larvae of this species were also tested on three young, naïve blackbirds, Turdus merula. The larvae were seized but not swallowed by the birds, and all tested larvae that were touched, curled their bodies immediately (see Fig. 2C) and survived the bioassay (Petre, personal observation). Thus, A. pagana can be considered as an aposematic species that is rejected by avian predators. We believe that the Arge larvae are protected by their pubescence that appears to physically irritate the gustatory sense of a bird and impede further handling. The fact that $A$. pagana larvae curl their body reinforces the effectiveness of the pubescence by producing a "hedgehog effect". It is not known whether the body colouration of Arge larvae has a defensive function also towards invertebrate predators. A couple of studies suggest that ants can learn by visual cues to avoid brightly coloured caterpillars (Dejean, 1988; Deml and Dettner, 2004).

The body pubescence of sawfly larvae can also provide a barrier against invertebrate attacks such as ant bites (Boevé et al., 2000). Furthermore, some argid larvae with a poorly developed pubescence present a particularly tough integument (Maxwell, 1955; Verhaagh, 1988). A South American sawfly species feeds on a myrmecophyte plant (a larval specimen received from Verhaagh was determined Argidae by Boevé). These argid larvae are apparently the only animals surviving to the presence of the very aggressive plant-inhabiting ants (Pseudomyrmex tachigaliae). Once disturbed, the larvae raise their abdomen and, with the tip of the abdomen, crush and kill any ant worker that bites their anterior region (Verhaagh, 1988). The defensive behaviour to raise the abdomen is common among nematine sawfly larvae which can, also by waving the abdomen, dislodge a biting ant (Boevé and Pasteels, 1985).

In addition to a physical protection, insects often use chemicals to defend against predation. Defensive exocrine glands are described from several insect groups (Whitman et al., 1990), and, more specifically, from nematine sawfly larvae (Boevé and Pasteels, 1985). Ventro-abdominal glands occurred in all Arge species studied (Table 2), but some other species possess either no one, or only one of these glands (Maxwell, 1955). Glands that were too minute may have been overlooked by this author (glands not mentioned for A. ochropus) and by us for gland VIII in A. nigripes. The ventral glands of A. pullata contain volatiles, since they emit a perceptible odour when crushed (Boevé, personal observation), and gas chromatography-mass spectrometry analyses of gland extracts from this species revealed the presence of aromatics among the most volatile compounds (Boevé, F. Müller and M. Hilker, unpublished results). We suppose volatiles from ventral glands of Arge larvae to be involved in 
defence since larvae raised their abdomen when disturbed, and since ants could retreat just by approaching a larva without contacting it. Volatiles such as aromatics are often used by insects as repellents (Laurent et al., 2005).

Ants retreated more often from L5-6 than L3-5 of A. pagana. This may indicate that, in the frame of bioassays, relatively large amounts of volatiles are necessary to clearly detect their repellent effect. In the nematine sawfly Hoplocampa testudinea as well, ants are repelled only when confronted to full-grown larvae, which compared to younger instars, possess especially large glands (Boevé et al., 1997). It is likely that if large amounts of volatiles are produced by A. pagana L5-6, which display aposematic body colours, then they may function more easily as a defence, not only towards invertebrates such as ants, but also towards predatory birds, as chemical warning signal. Such a function is known for odours emitted by caterpillars (Guilford et al., 1987). Beside a physical protection (see above), the L5-6 of A. pagana would combine visual and chemical warning signals.

The crude hemolymph of A. pagana proved a deterrent for ants. This sawfly feeds on roses, but we believe it is unlikely that sawflies sequester plant chemicals because roses are not known to contain harmful compounds (Buckingam, 1994). Thus, de novo production of such compounds is more plausible. Feeding deterrence was evidenced not only from the crude hemolymph, but also from extracts of several body parts (Table 3). Fat bodies plus salivary glands were not active and thus constituted an internal control for the other body parts tested. A large majority of tenthredinid species possess a hemolymph deterrence that is in the same order of magnitude as those in the tested Arge species (Boevé and Schaffner, 2003, Table 3). In the tenthredinids, this bioactivity is probably due to the co-occurrence of micromolecules (i.e., secondary plant metabolites) and macromolecules (e.g., proteins, with some entangling properties).

The paralysing effect of extracts from several A. pagana body parts was an unexpected bioactivity. This toxicity was not observed with crude hemolymph, probably since too few ant individuals fed on it (two ants, compared to 12 ants on the hemolymph extract) to have a chance of observing the symptom. The total amount of deterrent compounds would be expected to be higher in the crude hemolymph than in the hemolymph extracts. This would be especially the case for possibly deterrent macromolecules which are removed from the ethanolic extract by filtration. It is likely that the strong deterrent effect of crude hemolymph prevented its ingestion, whereas the dissolution of tested extracts in sugared water has stimulated ants to feed, and thus, to ingest the toxins. The precise origin and ecological relevance of such toxicity is subject to ongoing research. For A. pagana, the highest toxicity was obtained with the extract of the digestive tract (Table 4), which may indicate that the toxin(s) is/are produced by this body part. In A. pullata, extracts from fat bodies plus salivary glands were also toxic, but not deterrent (Table 3), which remains an unexplained result. The reverse was true with its hemolymph extract, which was probably too much of a deterrent to be toxic (see above). We suspect a peptidic toxin such as lophyrotomin (see Section 1) to be present in A. pagana. This toxin was detected in A. pullata (Kannan et al., 1988) from which total extracts proved to be deterrent towards ants. Since extracts from these two species provoked similar deterrence levels (Table 3), it is likely that the toxin occurs in both species, and, more generally, in other Arge species.

\section{Acknowledgements}

We thank Ewald Altenhofer for providing us with A. pullata larvae, as well as Chantai De Ridder, Julien Cillis and Philippe Willenz for their technical assistance in histological preparations, SEM and light microscopy photographing, respectively. We also warmly thank Herbert R. Jacobson, Jacques M. Pasteels and two anonymous reviewers for their valuable comments on the manuscript. C. Detrain is Senior Research Associate from the Belgian National Fund for Scientific Research.

\section{References}

Benson, R.B., 1950. An introduction to the natural history of British sawflies. Transactions of the Society for British Entomology 10 (Part 2 ), 48-142.

Boevé, J.-L., Müller, C, 2005. Defence effectiveness of easy bleeding sawfly larvae towards invertebrate and avian predators. Chemoecology 15, 51-58.

Boevé, J.-L., Pasteels, J.M., 1985. Modes of defense in nematine sawfly larvae. Journal of Chemical Ecology 11, 1019-1035.

Boevé, J.-L., Schaffner, U., 2003. Why does the larval integument of some sawfly species disrupt so easily? The harmful hemolymph hypothesis. Oecologia 134, 104-111. 
Published in: Journal of Insect Physiology (2007), vol. 53, pp. 668-675.

Status: Postprint (Author's version)

Boevé, J.-L., Gfeller, H., Schlunegger, U.P., Francke, W., 1997. The secretion of the ventral glands in Hoplocampa sawfly larvae. Biochemical Systematics and Ecology 25, 195-201.

Boevé, J.-L., Heilporn, S., Dettner, K., Francke, W., 2000. The secretion of the ventral glands in Cladius, Priophorus and Trichiocampus sawfly larvae. Biochemical Systematics and Ecology 28, 857-864.

Buckingam, J., 1994. Dictionary of Natural Products. Chapman \& Hall, London.

Chevin, H., 1972. Notes sur les Hyménoptères Tenthredoides. 2: Identification des larves d'Arge pagana (Panz.) et d'Arge ochropa (Gmel.). Bulletin Mensuel de la Société Linnéenne de Lyon 1, 2-4.

Dejean, A., 1988. Memory effect on predatory behavior of Odontomachus troglodytes (Formicidae-Ponerinae). Behaviour 107, 131-137.

Deml, R., Dettner, K., 2004. Defensive potenial of the colourful scoli and haemolymph from caterpillars of Hyalophora cecropia (Linnaeus, 1758) (Lepidoptera: Saturniidae). Entomologische Zeitschrift 114, 23-26.

Eisner, T., Johnessee, J.S., Carrel, J., Hendry, L.B., Meinwald, J., 1974. Defensive use by an insect of a plant resin. Science 184, $996-999$.

Fisher, R.A., 1930. The Genetical Theory of Natural Selection. Clarendon, Oxford.

Guilford, T., 1990. The evolution of aposematism. In: Evans, D.L., Schmidt, J.O. (Eds.), Insect Defenses: Adaptive Mechanisms and Strategies of Prey and Predators. State University of New York Press, Albany, NY, pp. 23-61.

Guilford, T., Nicol, C, Rothschild, M., Moore, B.P., 1987. The biological roles of pyrazines: evidence for a warning odour function. Biological Journal of the Linnean Society 31, 113-128.

Kannan, R., Oelrichs, P.B., Thamsborg, S.M., Williams, D.H., 1988. Identification of the octapeptide lophyrotomin in the European birch sawfly (Arge pullata). Toxicon 26, 224-226.

Laurent, P., Braekman, J.-C, Daloze, D., 2005. Insect chemical defense. Topics in Current Chemistry 240, $167-229$.

Lorenz, H., Kraus, M., 1957. Die Larvalsystematik der Blattwespen (Tenthredinoidea und Megalodontoidea). Akademie-Verlag, Berlin.

Marples, N.M., Vanweelen, W., Brakefield, P.M., 1994. The relative importance of color, taste and smell in the protection of an aposematic insect Coccinella septempunctata. Animal Behaviour 48, 967-974.

Maxwell, D.E., 1955. The comparative internal larval anatomy of sawflies (Hymenoptera: Symphyta). The Canadian Entomologist 89 (supplement 1), $132 \mathrm{pp}$.

Oelrichs, P.B., Vallely, P.J., MacLeod, J.K., Cable, J., Kiley, D.E., Simmons, R.E., 1977. Lophyrotomin, a new toxic octapeptide from the larvae of sawfly, Lophyrotoma interrupta. Lloydia 40, 209-214.

Pschorn-Walcher, H., 1982. Unterordnung Symphyta, Pflanzenwespen. In: Schwenke, W. (Ed.), Die Forstschädlinge Europas. Paul Parey, pp. 4-196.

Ruxton, G.D., Sherratt, T.N., 2006. Aggregation, defence and warning signals: the evolutionary relationship. Proceedings of the Royal Society B 273, 2417-2424.

Thamsborg, S.M., Jorgensen, R.J., Brummerstedt, E., 1987. Sawfly poisoning in sheep and goats. The Veterinary Record 121, 253-255.

Verhaagh, M., 1988. "Parasitierung" einer Ameisen-Pflanzen-Symbiose im neotropischen Regenwald? Carolinea 46, 150.

Wagner, M.R., Raffa, K.F. (Eds.), 1993. Sawfly Life History Adaptations to Woody Plants. Academic Press, New York.

Whitman, D.W., Blum, M.S., Alsop, D.W., 1990. Allomones: chemicals for defense. In: Evans, D.L., Schmidt, J.O. (Eds.), Insect Defenses: Adaptive Mechanisms and Strategies of Prey and Predators. State University of New York Press, Albany, NY, pp. $289-351$.

Williams, D.H., Santikarn, S., Oelrichs, P.B., De Angelis, F., Macloed, J.K., Smith, R.J., 1982. The structure of a toxic octapeptide, containing 4 D-amino-acids, from the larvae of the sawfly, Lophyrotoma interrupta. Journal of the Chemical Society, Chemical Communications 1012, 1394-1396. 